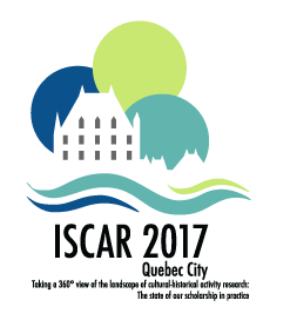

\title{
Inviting Russians Scholars to Reflect on Vygotsky's Heritage
}

Sylvie Barma

Faculté des sciences de l'éducation

Université Laval

Québec, Canada

Viktor K. Zaretskii

Moscow State University of Psychology and Education

Moscow, Russia
SYLVIE.BARMA@FSE.ULAVAL.CA

ZAR-VICTOR@YANDEX.RU

The International Journal of the Centre of Research and Intervention for Student and School Success (CRI_SAS): To innovate in Vygotsky's heritage is a journal that focuses on the innovation and transformation of learning environments related to the educational success of young people. It invites researchers and graduate students to propose theoretical texts, reflections on methodological issues or empirical research results based on the idea that individuals learn and develop through social mediation and use transformation of artefacts from the culture within which they pursue a given activity. Eligible contributions are therefore in line with Vygotsky's work and are based on theories of language (speech), situational cognition, socio-cultural approaches and formative research interventions. The launching of this Special Issue coincides with the 25th anniversary of CRI_SAS. It is therefore an opportune time to promote our free online distribution of scientific and professional texts. As editors, we are also thankful for the financial support provided to the editing team lead by Marie-Caroline Vincent.

The ISCAR 2017 conference decided to take a 360 view of the Society's landscape. It was thus an opportunity to reach out at the roots of cultural-historical theory and to invite scholars from Russia to contribute to a Special Issue to better grasp the state of our scholarship in practice. The congress theme invoked the past, the present, and the future of cultural-historical activity research and it is with that intention that the two editors invite you to enjoy reading our Special Issue. We hope that it will allow you to engage in challenging conversations issues that could lead to revisit ideas or expand upon our current practices. We propose 22 articles written by more than 24 Russian authors.

The first section of the Special Issue addresses questions related to translation and dissemination of Vygotsky's ideas. One of the challenges we faced was to translate Russian texts to English. This is why the first article by Olga Tuchina raises some interesting issues about translating, as the importance of language and culture has always been at the core of 
Vygotsky's work. The second article by Anna A. Shvedovskaya presents the analysis of the development of the ideas of L. S. Vygotsky's school using the example of the publications in the international scientific journal 'Cultural-Historical Psychology', for the period 2005 through 2016.

The second section Theoretical and Methodological issues gathers 7 articles. We begin with Vitaly V. Rubtsov, who reflects on Davydov's opinion on the legacy of Vygotsky's students: A. N. Leontiev, A. R. Luriya, L. I. Bozhovich, A. V., Zaporozhets, D. B. Elkonin and P. Y. Galperin. Then, Elena Kravtsova takes us to Lev Vygotsky to better understand the sense and the meaning of cultural and historical theory. Nataliya N. Tolstykh focuses on the concept of will as an open problem and related to how A. Leontiev and L. Bozhovich developed original personality concepts based on Vygotsky's most prominent ideas. Marina Falikman and Alexander Asmolov see the problem of consciousness as one of the core problems in contemporary science to consider attention as a constructive process. For Stanislav M. Morozov, Vygotsky's cultural-historical psychology contains a significant methodological potential, rather than just a scientific theory. For Dmitry V. Lubovsky, art, as a system of means, can be powerful to develop higher mental functions during childhood and adolescence, periods which require a great attention by teachers and parents. Vladimir S. Sobkin situates his reflections during the Gomel period when Vygotsky analyzed the socio-psychological mechanisms of theatrical art effect.

The third section Development brings together 8 articles. The article of Viktor Zaretskii is devoted to one of fundamental Vygotsky's ideas, that one step in education may mean one hundred steps in development. There are provided theoretical arguments and are given examples of how this idea may be implemented in practice of providing conditions for development while helping children in overcoming learning difficulties using reflectiveactivity approach.

Viktor Zaretskii and Alla Kholmogorova, in their article, analyse the process of conversion of some ideas in cultural-historical psychology and contemporary tendencies in psychotherapy. The ideas of reflection, position of agency, collaboration in the zone of proximal development and problem epicenter are discussed in educational, practice, counselling psychology and psychotherapy. The concept of dual resource is worked out (the first resource is what a child/client can do by himself, the second is what they can do in cooperation with an adult/psychotherapist).

Irina Nicolayevska describes a multidimensional model of the zone of proximal development, worked out in reflective-activity approach, as a tool of analysis of the child's cognitive-personal dynamics of development while overcoming learning difficulties. The case study of creating conditions for development in individual work with teenagers is described.

The article written by Oksana Glukhova is devoted to the longitudinal (2004-2017) research on cognitive development of children from primary school who participated in the project "Chess for Overall Development", guided by Viktor Zaretskii. The article describes the methodology for studying the dynamics of increasing the level of development of 
intellectual processes in children learning to play chess with the help of the reflectiveactivity approach.

Aleksei Chernysh tells about the computer program, "Chess for Overall Development", that was planned and realised as a current technological version of the ideas and methodological concepts making up the methodics of the same name. A crucial part of the planning process was the program's compatibility with the principles of the reflective-activity approach. The program, created as a powerful, resilient and convenient instrument, allows each student to progress along an individually constructed developmental path. Teachers using the program can quickly and accurately understand and define the limits of the zone of proximal development.

The concept of subjectness position relative to educational activities is considered in the article of Yury Zaretsky as central for the reflexive-activity approach. The author's definition of this concept is given. The main results of the research concerning the attitude towards educational activities in different age periods among Russian school's pupils are given, which show that, on the one hand, it is the subjectness position that is extremely important for many aspects of educational activities, but, at the same time, the Russian pupils' subjectness position intensity decreases in the adolescent period. The author describes possibilities and ways to support the subjectness position in educational process.

Elena Smirnova shows in her paper the specificity of L. S. Vygotsky's approach to child play and toy as the tool of play. Vygotsky paid special attention to pretend play, the essence of which consists in a divergence between the imagined and the real situations. Such play promotes the development of imagination, thinking, self-control, voluntary behavior, selfawareness, social interrelationship and emotional intelligence. The main tools of a child's play are toys. It is indicated that the good toys should be open for various actions and the ideas of the child. However, the majority of modern toys are equipped with technical devices which do not allow the child to show his/her own activity. Playing with such toys comes down to a putting button that, unlike a pretend play, doesn't develop the abilities of the child.

The last article in this section, written by Marina Ermolaeva, is devoted to the analysis of old age as a cultural-historical phenomenon and its transformation in modern times. The author shows that the term "old age" means different periods of life for different authors, and there is no general, identical for all people, final stage of life. Development trajectories, which are defined by a way of life, are so different that the concept of "old age" in one case means "the undergoing" suffering of total dependence on the conditions of existence and their own condition's deterioration, and, in another case, the continuation of progressive development of personality, productivity, and spirituality of life, which are realized in actions.

The fourth section Clinical Psychology, psychotherapy and training includes 5 articles. Cultural-historical approach and clinical psychology were very close to each other from the very beginning, L. S. Vygotsky worked a lot upon different problems of pathology in development. But, until last years, it seemed that cultural-historical psychology was 
not connected with psychotherapy. In the articles of the fourth section, this thesis is refuted. The paper by Alla Kholmogorova provides a comparative analysis of the basic methodological principles of cognitive therapy and cultural-historical psychology. There are discussed the history of studying reflection in Moscow Psychological School and the scheme of a reflective act as the most important concept yielded by these studies. On the basis of this scheme, the author proposes the steps of a cognitive therapist's work and the mechanisms of change in cognitive therapy.

In her paper, Maria Radionova tries to interpret the effectiveness mechanism of a 12-step program in the recovery of addicts. This analysis leads the author to the conclusion that the stimulation and development of the subjective position of the convalescent manifest themselves in the early stages of recognizing the illness and assuming responsibility for recovery, and, further on, in mastering one's own behavior. Changes in the life of the addict proceed according to several vectors of development: managing their psycho-emotional state, reassessing past life experience, correcting relationships with people, resolving current problems without psychoactive substances, the ability to receive and provide social support, the development of empathy.

The aim of Elena Yangicher is to work out a model of development of constructive response to frustration of adolescence from socially advantaged and disadvantaged groups using art-therapy methods. The author comes to the conclusion that instruments of psychological influence can be considered special means of art therapy methods that contribute to the directed formation of positive mental states and reactions in adolescence and facilitate integration of positive (resource) mental states into the process of formation of new reactions, as well as realise the adolescent's need for self-expression (in constructive forms) preventing and reducing elevated frustration.

Alexey Obukhov's article is devoted to the problems of teachers' training as based on Vygotsky's idea that development is the process of mastering culture. There are described in the practice of creating a new educational system in Moscow Pedagogical State University. The problems and results of the effort to organize the educational process on the ideas of supporting subjectiveness position, developing of reflection, moving in the zone of proximal development are discussed in the paper.

This first experience between our two universities has been an adventure. We are thankful to all the contributing authors, who managed to engage in elaborating their ideas in a very short time. We hope that this Special Issue is just the beginning of an oncoming collaboration for the benefit of the disciples of Vygotsky. Our intention is to open up a channel so the International Scientific Community has access to the state of the research in Russia knowing well that nowadays, there are many other interesting approaches to Vygotsky's tradition that are not presented in this Special Issue.

Sylvie Barma

Viktor Zaretskii 

